\title{
NEUROLOGY IN MEDICINE
}

\section{Neurology and the blood: haematological abnormalities in ischaemic stroke}

\author{
Hugh S Markus, Henry Hambley
}

Haematological disorders account for up to $8 \%$ of all ischaemic strokes in different series. Table 1 shows the haematological disorders associated with ischaemic stroke. Most studies report them as being more common in younger stroke patients, particularly those who have undetermined stroke aetiology after extensive tests including full cardiac evaluation. Many primary haematological disorders have been associated with ischaemic stroke but in many patients with stroke other aetiological factors are also present making a cause and effect relation difficult to prove. Furthermore, some of these haematological factors, particularly deficiencies of natural anticoagulants, are more potent causes of venous thrombosis. Therefore in such cases paradoxical embolism from the venous system should be considered, and excluded, before arterial thrombosis is implicated.

\section{Normal haemostatis}

The haemostatic system is a major defence system of the body. It is the result of interaction of three components: (1) the vessel wall, particularly endothelial cells; (2) platelets; and (3) the coagulation system including the fibrinolytic system.

Keywords: haematological abnormalities; ischaemic stroke

Department of Clinical Neuroscience, King's College School of

Medicine and Dentistry London, UK H Markus

\section{Department of} Haematology, King's Healthcare, Denmark Hill, London, UK H Hambley

Correspondence to: Dr H S Markus, Department of Clinical Neuroscience, Institute of Psychiatry, De Crespigny Park, Denmark Hill, London SE5 8AF, UK. Telephone 01713465174 ; fax 0171 919 3407; email

h.markus@iop.bpmf.ac.uk

Received 18 August 1997 Accepted 22 August 1997
Table 1 Haematological disorders associated with ischaemic stroke

Cellular disorders:

Polycythaemia rubra vera

Essential thrombocythaemia

(b) Sickle cell disease

(c) Paroxysmal nocturnal haemoglobinuria

(d) Thrombocytopenia

(f) Intravascular lymphoma

Disorders of coagulation/fibrin

(a) Congenital:

Natural anticoagulant disorders:

Protein C deficiency

Protein $\mathrm{S}$ deficiency

Activated protein $\mathrm{C}$ resistance

Antithrombin III deficiency

Fibrinolytic system disorders:

Plasminogen deficiency

Disseminated intravascular coagulation

Lupus anticoagulant/anticardiolipin syndrome

Pregnancy and the puerperium

Oral contraceptive pill

Paraproteinaemias (a) Myeloproliferative:

(e) Leukaemia

(b) Acquired:
The aims are to maintain fluidity of the blood and, when there is a break in the integrity of the vessel wall, to rapidly initiate blood coagulation which is maintained locally at the site of vascular damage. The process involves several different proteins. Defects of these, which may be congenital or acquired, will result in disorders of haemostasis which may manifest in clinical syndromes of easy bleeding or bruising ("haemophilias") or inappropriate thrombosis ("thrombophilia"). A more general breakdown in the initiation and control of haemostasis results in the syndrome of "disseminated intravascular coagulation", in which there is the apparent paradox of concurrent bleeding and widespread thrombosis which is responsible for much of the organ damage.

The vascular endothelium plays a critical part in maintaining blood fluidity and vascular smooth muscle tone through (a) prostacyclin, a potent vasodilator and platelet antiaggregator synthesised from arachidonic acid through a series of steps, including involvement of cyclooxygenase, which is inhibited by aspirin ${ }^{1}$;

(b) nitric oxide (endothelium derived relaxing factor, EDFR), which is a potent vasodilator and inhibits platelet aggregation. It is not inhibited by aspirin but is inhibited by free haemoglobin. ${ }^{2}$

In addition, thrombomodulin is expressed on the surface of endothelial cells and plays a critical part in the inhibition of fibrin formation through its interaction with thrombin and protein C. Thrombomodulin is reduced on endothelial surfaces in response to hypoxia. Mild hyperhomocysteinaemia may result in inhibition of thrombomodulin and thus explain the increase in thrombosis seen in this condition.

Platelets are anucleate cells derived from megakaryocytes in the bone marrow. Their production is regulated in part by thrombopoietin (TPO), also known as megakaryocyte growth and development factor (MGDF). Activation of platelets brought about by exposure to subendothelial collagen results in changes including shape change, aggregation, and release of intracytoplasmic granule contents.

Functionally these changes result in:

(1) Formation of a primary platelet plug at the site of vascular injury. 
(2) Thromboxane A2 synthesis. This causes vasoconstriction and further platelet aggregation, thus augmenting the primary platelet plug.

(3) Release of coagulation proteins including thrombin, factor V, and von Willebrand factor.

(4) Exposure of phospholipid membrane and other receptors, which is important in the coagulation cascade and interactions with neutrophils and monocytes and other platelets via fibrinogen and von Willebrand factor.

The coagulation cascade model with its division into intrinsic and extrinsic pathways has largely stood the test of time. ${ }^{34}$ Recent advances have emphasised the importance of the tissue factor driven extrinsic pathway as the prime activator of coagulation. Tissue factor is a ubiquitous protein, with the exception of the vascular compartment. Only activated neutrophils and monocytes express tissue factor in the blood and the endothelium can be seen as a simple barrier preventing interaction between tissue factor and the coagulation system. The intrinsic pathway probably functions to amplify the formation of the tenase complex. The other major advance in our understanding has been regarding the role of the inhibitors of coagulation and their interaction with other systems. Antithrombin is a major inhibitor of thrombin. It combines in a $1: 1$ complex with thrombin and this interaction is enhanced by heparin. As a member of the serpin family, it also inhibits other serine proteases including factors $\mathrm{X}, \mathrm{XIa}$, and IXa (FX, FX1a, and FIXa). Activated protein $\mathrm{C}$ plays an important part in inactivating FVa and FVIIIa. As FV is an important part of the tenase, activated protein $\mathrm{C}$ plays a pivotal part in down regulating thrombin generation. Tenase is the complex of activated factor $\mathrm{V}$ and $\mathrm{X}$ which binds to the phospholipid surface in the presence of calcium and results in a several fold increase in the activity of factor $\mathrm{X}$ compared with unbound factor $\mathrm{X}$. Thrombin is rapidly bound to the endothelial surface protein thrombomodulin. On binding, thrombin loses its ability to split fibrinogen and instead becomes a potent activator of protein C. Activated protein $\mathrm{C}$ in association with protein $\mathrm{S}$ inactivates $\mathrm{FVa}$ by cleaving the heavy chain of FVa at position 506. Substitution of the normal arginine by glutamine at position 506 removes one of the cleavage sites of activated protein $\mathrm{C}$ resulting in increased thrombin generation. Antiphospholipid antibodies may act by interfering with the inactivation of FV by activated protein C. Protein S, as well as acting as a cofactor for protein $C$, is able to inactivate $\mathrm{FVa}$ directly at another arginine cleavage site (306) and may also remove activated protein $\mathrm{C}$ protection factors allowing activated protein $\mathrm{C}$ to inactivate $\mathrm{FVa}$. Protein $\mathrm{S}$ has no proteolytic activity (figs 1 and 2).

\section{Cellular disorders}

MYELOPROLIFERATIVE

Polycythaemia rubra vera

Polycythaemia rubra vera is a myeloproliferative disorder resulting from clonal expansion of a transformed haematopoetic stem cell associated with pronounced overproduction of red blood cells and, to a lesser extent, expansion of granulocytic and megakaryocytic elements. It usually begins in late middle age. The increased packed cell volume results in hyperviscosity and reduced cerebral blood flow. This may result in cerebral infarction: transient ischaemic attacks or intracranial venous thrombosis. Stroke rates of about $5 \%$ a year have been reported. ${ }^{5}$ Other neurological symptoms include headache, dizziness, visual blurring, and confusion resulting from a reduction in cerebral blood flow secondary to hyperviscosity. Treatment may involve phlebotomy, hydroxyurea, and other cytotoxic drugs.

Secondary polycythaemia may be caused by chronic hypoxia, often occurring, for example, in patients with congenital cyanotic heart disease, smoking, cerebellar hemangioblastoma, renal tumours, and patients who smoke. It has been suggested that this is a risk factor for stroke but if this is the case it seems to be only weakly associated. Furthermore the association is confounded by cigarette smoking and blood pressure, both being linked to packed cell volume. Studies have shown no increased risk of stroke in young adults with cyanotic congenital heart disease and secondary polycythaemia ${ }^{6}$ or in perioperative thrombotic risk in 100 patients with secondary polycythaemia. $^{7}$

\section{Essential thrombocythaemia}

Essential thrombocythaemia is a myeloproliferative disorder in which blood platelet counts above 600000 cells $/ \mathrm{ml}$ occur. In addition the platelets are often large and have functional abnormalities. Occasionally such abnormalities of platelet function result in a bleeding tendency but thrombosis is more common. Stroke is a well recognised complication but headache and transient focal and non-focal neurological disturbances are also frequent. ${ }^{8-10}$ Essential thrombocythaemia must be distinguished from secondary thrombocythaemia, which can occur in response to conditions including inflammation, acute bleeding, iron deficiency, splenectomy, and infection. A highly increased platelet count in the absence of an identifiable cause of secondary thrombocythaemia is usually sufficient for a diagnosis of essential thrombocythaemia. Support for the diagnosis may be obtained by in vitro platelet aggregation studies and the documentation of splenomegaly. In essential thrombocythaemia the megakaryocytes are large and hyperploid by contrast with secondary thrombocythaemia when they are usually increased in number and of small diameter and low ploidy.

The management of essential thrombocythaemia requires specialist care and hydroxyurea is often used as an initial treatment. The use of antiplatelet agents such as aspirin is controversial. These may protect against thrombosis but can also increase the risk of haemorrhage. Control of the platelet count is of primary importance but in the occasional patients in whom good control cannot be achieved, or who develop thrombotic complications despite adequate lowering of the plate- 
The coagulation cascade

Extrinsic pathway

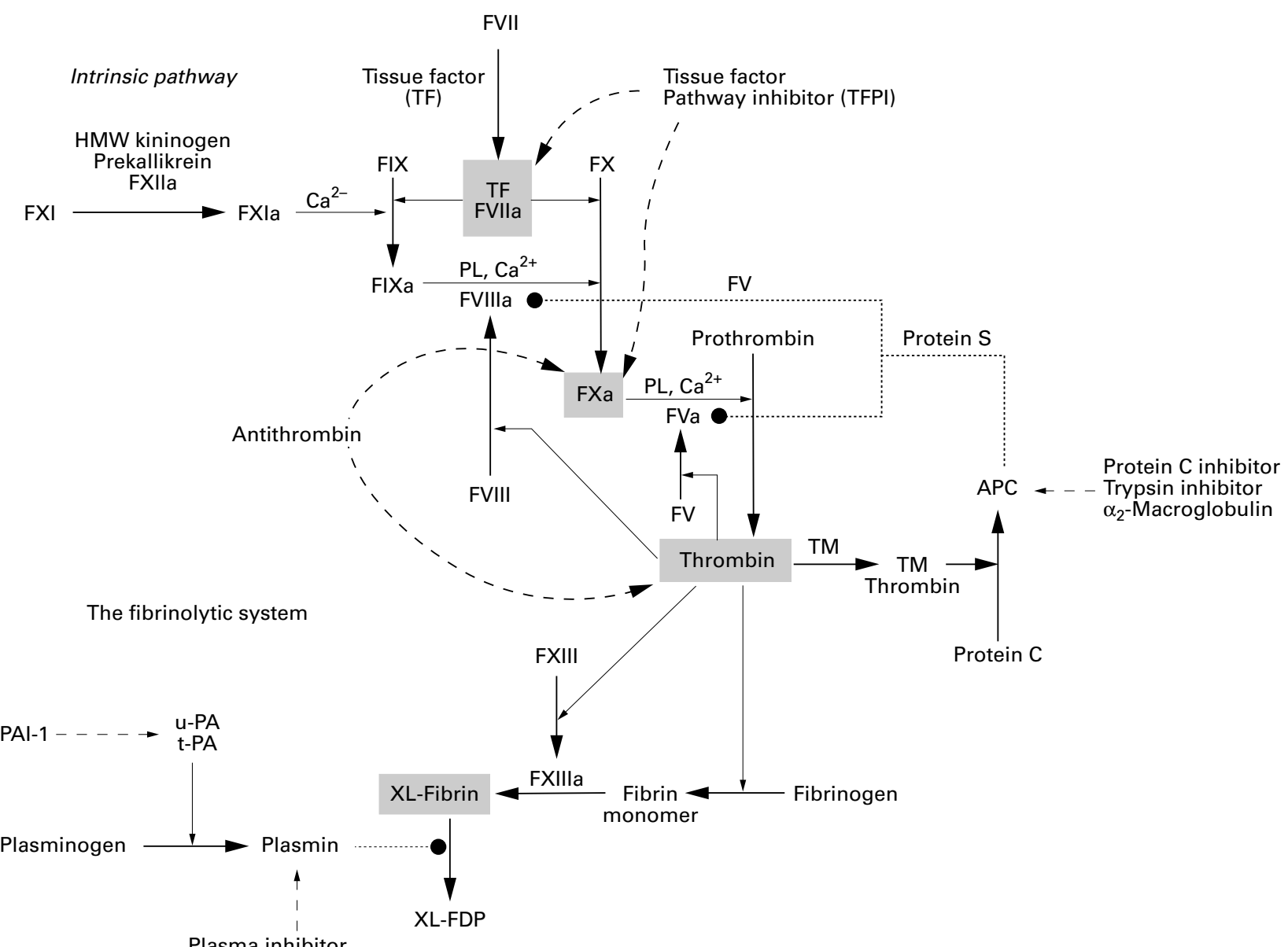

Plasma inhibitor

Activation
Inhibition
Inactivation
Degradation
Strategic components

Abbreviations
$F=$ factor
$a=$ active
$T M=$ thrombomodulin
$P L=$ phospholipid
$H M W=$ high molecular weight
$A P C=$ active protein $C$
$X L=$ crosslinked
FDP = fibrin degradation products

Figure 1 The coagulation cascade. Vascular damage initiates coagulation cascade resulting in the explosive generation of thrombin at the site of injury. Thrombin catalyses the conversion of fibrinogen to an insoluble fibrin (clot) matrix, in the presence of factor XIIIa and calcium ions. Critical reactions are closely checked and localised by circulating anticoagulants, such as activated protein C, TFPI, and antithrombin. Fibrinolysis is initiated when fibrin is formed and eventually dissolves the clot. Inappropriate activation of blood coagulation, or depressed fibrinolytic activity, or both may lead to the formation of a thrombus. By contrast, a defect or deficiency in the coagulation process andlor accelerated fibrinolysis is associated with a bleeding tendency. The cascade scheme is organised into the intrinsic (factors XII, XI, IX, VIII, prekallikrein, HMW kininogen), extrinsic (tissue factor, factor VII), and common pathways (factors V,X, XIII, prothrombin, fibrinogen). The extrinsic pathway is initiated when blood is exposed to tissue factor released from damaged endothelium. The intrinsic pathway is initiated by the activation of factor XII involving "contact factors" on negatively charged surfaces, such as glass or kaolin in vitro. Feedback activations of factors V, VII, and VIII by factor Xa and the activation of factor XI by thrombin are not shown. (From APC Resistance, version 2.0 1997 Chromogenix AB, Taljegärdsgatan 3, S-431 53 Mölndal, Sweden, with permission.)

let count, the addition of low dose aspirin may be warranted.

SICKLE CELL DISEASE

Stroke is a frequent complication of homozygous sickle cell disease, particularly in children. ${ }^{11}{ }^{12}$ One study suggested that $75 \%$ of cerebrovascular complications in sickle cell patients occurred in those under 15 years of age $^{11}$ whereas another study found cerebral ischaemia in $15 \%$ of homozygotic Hb6SS patients with a mean age of onset of 15 years. ${ }^{5}$ However, the prevalence of silent infarction on brain imaging is higher. ${ }^{13}$ The mechanism of stroke is often unclear although changes during sickle cell crisis, such as raised whole blood viscosity and red blood cell abnormalities may result in small and large arterial occlusions. In addition, stenosis of large extracranial or intracranial vessels may occur secondary to fibrous proliferation of the intima. Stenoses in the middle cerebral artery can be detected by transcranial Doppler and their presence predicts risk of stroke. ${ }^{14}$ This technique may allow identification of at risk people in whom a programme of exchange transfusion can prevent 


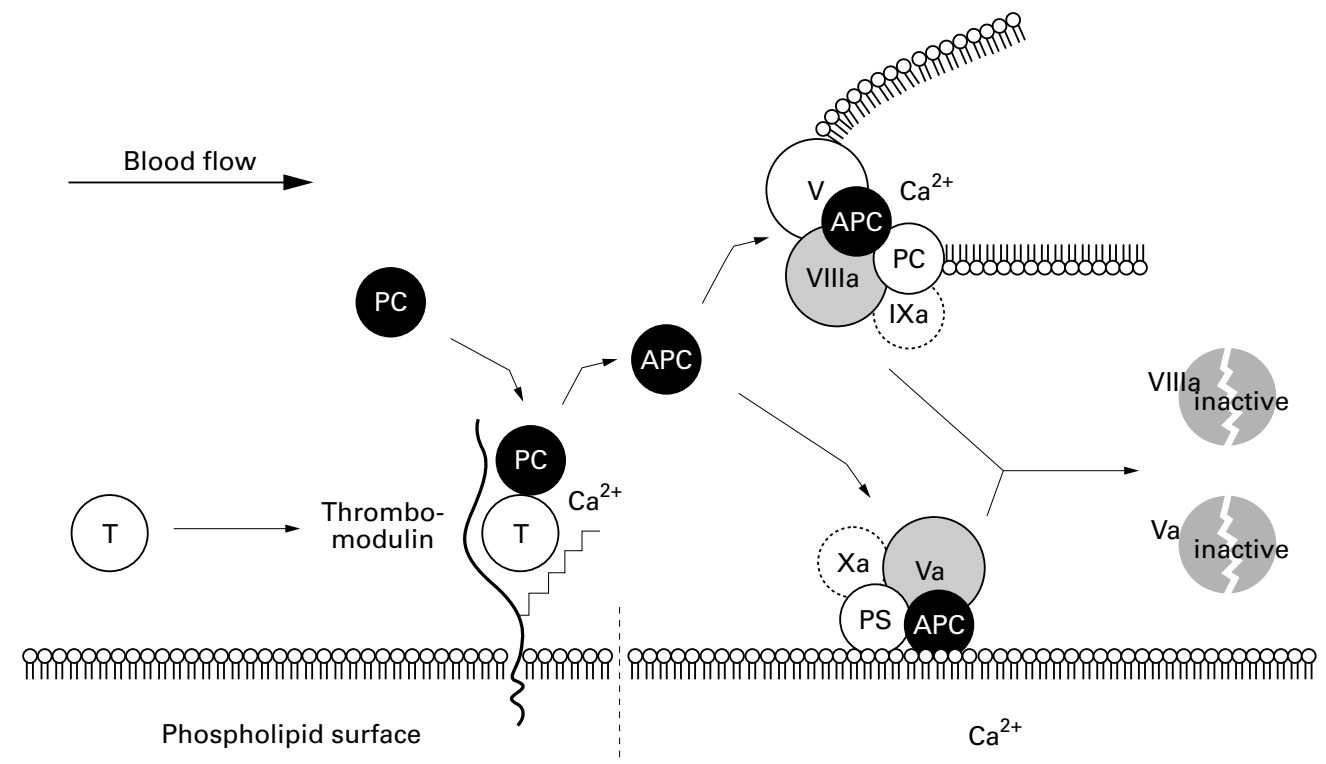

Figure 2 The protein $C$ anticoagulant pathway. Thrombin escaping from a site of vascular injury binds to its receptor thrombomodulin (TM) on the intact cell surface. As a result, thrombin loses its procoagulant properties and instead becomes a potent activator of protein C. Activated protein $C$ (APC) functions as a circulating anticoagulant, which specifically degrades and inactivates the phospholipid-bound factors Va and VIIIa. This effectively down regulates the coagulation cascade and limits clot formation to sites of vascular injury. The activity of APC is potentiated by two cofactors, protein $S$ and native (non-activated) factor V. Protein S functions as a cofactor in the degradation of factor Va and VIIIa. Native factor $V$ acts in synergy with protein $S$ as a cofactor in the degradation of factor VIIIa. Thus factor $V$ has dual roles one as anticoagulant in its native form and the other as an procoagulant after its activation. APC is slowly neutralised by circulating inhibitors. Thrombin bound to TM is eventually inhibited by antithrombin or removed through endocytosis of the thrombin/TM complex. T=thrombin; $P C=$ protein $C ; P S=$ protein $S$. (From APC Resistance, version 2.01997 Chromogenix AB, Taljegårdsgatan 3, S-431 53 Mölndal, Sweden, with permission.)

stroke. Occlusion of large intracerebral arteries in sickle cell disease may result in a MoyaMoya-like syndrome which can present often in young adults with subarachnoid haemorrhage. The mainstay of treatment of cerebrovascular complications in sickle cell disease is exchange transfusion.

Stroke may also complicate haemoglobin sickle cell disease. ${ }^{15}$

PAROXYSMAL NOCTURNAL HAEMOGLOBINURIA Paroxysmal nocturnal haemoglobinuria is a rare disorder which is an acquired clonal disease in which red cells show increased sensitivity to lysis by complement. ${ }^{16}$ The complement activation indirectly stimulates platelet aggregation and hypercoagulability, which is probably responsible for the tendency to thrombosis. Patients present with a haemolytic anaemia, and often mild lymphopenia and thrombocytopenia. Haemoglobinuria may occur. The diagnosis can be made by the Ham test in which sensitivity of the patient's cells to lysis by complement can be shown or with CD59 assessment by flow cytometry. Cerebral venous thrombosis may occur; stroke is occasionally part of the syndrome. ${ }^{17}$

THROMBOCYTOPENIA

Thrombotic thrombocytopenic purpura is a rare but often fatal disorder characterised by thrombocytopenia, a microangiopathic haemolytic anaemia, renal failure, fever, and neurological symptoms. It may be initiated by endothelial injury and subsequent release of Von Willebrand factor and other procoagulant materials from the endothelial cells. In addition in some patients circulating protein may induce platelet aggregation. ${ }^{16}$ Many of the symptoms are due to widespread small platelet microthrombi which cause infarction in many organs including the brain. Neurological symptoms include a fluctuating encephalopathic picture with confusion and seizures and this can be accompanied by focal symptoms and signs. ${ }^{18} 19$ However, it can occasionally present with isolated stroke or transient ischaemic attack. The thrombocytopenia on full blood count will point to the diagnosis. Brain CT may be normal or show infarction and occasionally intracerebral haemorrhage. ${ }^{20}$

Thrombotic thrombocytopenic purpura is similar to haemolytic-uraemic syndrome, which usually occurs in children less than 5 years old. This multisystem disorder presents with fever, thrombocytopenia, a microangiopathic haemolytic anaemia, hypertension, and varying degrees of renal failure. Hyaline thrombi are particularly seen in the afferent arterioles and glomerular capillaries of the kidneys and neurological symptoms, other than those associated with uraemia, are less common but can still occur. ${ }^{21}$

Treatment for thrombotic thrombocytopenic purpura involves exchange transfusion or extensive plasmapheresis coupled with infusion of fresh frozen plasma. This therapeutic approach has led to a considerable reduction in the overall mortality with over half of the patients with thrombotic thrombocytopenic purpura recovering.

Heparin induced thrombocytopenia

It has been estimated that as many as $10 \%-15 \%$ of patients receiving therapeutic doses of heparin may develop a degree of 
thrombocytopenia. ${ }^{22}$ This may occur due to drug-antibody binding to platelets or occasionally secondary to direct platelet agglutination by heparin. It may lead to severe bleeding or intravascular platelet aggregation and paradoxical thrombosis. Stroke may occur. ${ }^{23}$

\section{LEUKAEMIA}

Leukaemia more often causes intracerebral haemorrhage due to thrombocytopenia or direct leukaemic infiltration of the CNS, than arterial occlusion. When stroke does occur it is thought to be due to increased blood viscosity. $^{24}$

INTRAVASCULAR LYMPHOMA

Intravascular lymphoma is an uncommon malignancy, defined pathologically by neoplastic proliferation of lymphoid cells within the lumens of capillaries, small veins, and arteries with little or no adjacent parenchymal involvement. ${ }^{25}$ It used to be called malignant angioendotheliosis but recent immunohistochemical studies have demonstrated that the tumours are neoplastic lymphoid cells more commonly of B-cell origin and therefore it is now referred to as intravascular lymphoma or angiotrophic large cell lymphoma. Most commonly symptoms are confined to the skin or CNS until later stages of the disease when systemic features may develop. ${ }^{26}$ A literature review of 114 patients found that $63 \%$ had neurological manifestations without abnormalities on bone marrow biopsy, chest and abdominal CT, or CSF examination. ${ }^{27}$ One neurological presentation is with recurrent stroke-like episodes. ${ }^{28}$ It may also present with a dementia with or without focal neurological signs, a spinal cord syndrome, and peripheral or cranial neuropathies. ${ }^{27}$ It may produce an identical clinical picture to primary angiitis of the CNS, including similar angiographic appearances, and distinction may only be possible on brain biopsy or postmortem. ${ }^{29}$ Similarly the peripheral nervous system findings may mimic systemic vasculitis and again only be differentiated on biopsy. ${ }^{30}$ Autoantibodies may occur which can make distinction from vasculitis even more difficult. Most of the cases of CNS involvement have been diagnosed at postmortem. In some cases an improvement has been made after corticosteroid therapy although this may only be partial or transient. Chemotherapy has resulted in remission in a few case reports. ${ }^{26}$

\section{Disorders of coagulation/fibrin}

CONGENITAL

Natural anticoagulation disorders

The natural anticoagulants (heparin cofactor 2, antithrombin III, protein C, and protein S) inhibit thrombosis in the normal subject. Deficiencies of these anticoagulants may be hereditary or acquired. Such deficiencies may be responsible for as many as $20 \%$ of nontraumatic venous embolisms ${ }^{31}$ but their role in arterial thrombosis remains unclear. Many case reports have suggested an association but more controlled studies have often failed to prove this. Heparin cofactor 2 has probably only a minor role in venous thrombosis, and there are no convincing data linking it with arterial thrombosis.

\section{Protein $C$}

Protein $\mathrm{C}$ is a vitamin $\mathrm{K}$ dependent protein which binds to the endothelial cell surface protein thrombomodulin and is converted to an active protease by thrombin. Activated protein $\mathrm{C}$, in conjunction with protein $\mathrm{S}$ protolyses factor Va and factor VIIIa, which reduces thrombin formation. Activated protein $\mathrm{C}$ may also promote fibrinolysis and accelerate clot lysis. Protein $\mathrm{C}$ is synthesised in hepatocytes and its synthesis is encoded by a single gene located on chromosome 2 . Hereditary protein C deficiency is usually an autosomal dominant disorder although dysfunctional molecules have also been identified in some patients with thrombosis. ${ }^{22}$ Heterozygotes with $25 \%-50 \%$ of protein $\mathrm{C}$ concentrations occur in about 1 in 300 to 1 in 3000 unselected blood donors, ${ }^{32}{ }^{33}$ but many of these people are asymptomatic. Symptomatic deficiency is much less common, occurring in perhaps as few as 1 in 36000 people. ${ }^{34}$

There are many reports of protein C deficiency associated with ischaemic stroke. ${ }^{35-41}$

In young patients with stroke and protein $\mathrm{C}$ deficiency, who also have a strong family history of premature thrombosis, it is likely that the relation between protein $\mathrm{C}$ deficiency and the stroke is causal. However, often in older patients with moderate degrees of protein $\mathrm{C}$ deficiency, determining whether the association is causal can be difficult. The correlation between protein $\mathrm{C}$ and protein $\mathrm{S}$ concentrations and the risk of thrombosis is not as precise as for antithrombin III deficiency, and protein $\mathrm{C}$ concentrations in asymptomatic deficient people overlap with those seen in patients with recurrent thromboembolism. ${ }^{22}$ Furthermore, in the acute stage of stroke low concentrations of protein $\mathrm{C}$ are fairly common and may reflect consumption. The degree of reduction in protein $\mathrm{C}$ concentration has been associated with the severity of stroke. ${ }^{42}$ Serial sampling has shown that protein $\mathrm{C}$ concentrations may return to normal some months after stroke. ${ }^{43}$ Therefore, if low protein $\mathrm{C}$ concentrations are found in the acute phase of stroke measurement should be repeated after three months and family members should be tested. Apart from patients with extensive thrombosis or stroke, secondarily low protein C concentrations may occur in severe liver disease, the nephrotic syndrome, disseminated intravascular coagulation, in the postoperative period, and in patients receiving warfarin. ${ }^{44}$

It is generally recommended that patients with primary protein $\mathrm{C}$ deficiency and stroke should be heparinised and treated with oral anticoagulants. Whether these should be continued lifelong remains uncertain. Warfarin therapy itself will reduce protein C concentrations making determinations of concentrations while on therapy difficult.

An association has been reported between warfarin induced skin necrosis and protein $C$ deficiency. This is a rare but serious complica- 
tion of warfarin. It usually presents with localised pain followed by a petechial rash and ecchymoses. This can progress to widespread full thickness skin necrosis. If these symptoms appear during warfarin therapy the drug should be discontinued and vitamin $\mathrm{K}$ injected parentarally. Heparin can be given safely.

Protein $S$ deficiency

Protein $\mathrm{S}$ is a vitamin $\mathrm{K}$ dependent plasma glycoprotein which serves as a cofactor for activated protein C. It is synthesised primarily in the liver and encoded on chromosome 3 . In plasma about $60 \%$ is bound to a C4b-binding protein and $40 \%$ is in an active free form. Therefore for full assessment both total and active or "free" protein $S$ need to be measured. It has been estimated that protein S deficiency occurs in 1 in 3000 to 1 in 15000 people. ${ }^{45} 33$ Hereditary protein $S$ deficiency is an important cause of idiopathic venous thrombosis and may account for $5 \%$ or more cases. ${ }^{34}$

Some case reports and small series have reported an association between protein $\mathrm{S}$ deficiency and ischaemic stroke. ${ }^{35} 38$ 46-49 However, the same difficulties occur as in interpreting the association between protein $\mathrm{C}$ and stroke. Protein $\mathrm{S}$ concentrations may fall in ill patients both with stroke and admitted to hospital for other reasons. ${ }^{50}$ Therefore as for protein $\mathrm{C}$, follow up concentrations after three months and screening of family members is necessary. In the presence of persistent protein $S$ deficiency in stroke the recommended treatment is anticoagulation. Low protein $\mathrm{S}$ concentrations may also occur with pregnancy, warfarin therapy, and acute illness, whereas women have lower concentrations of protein $S$ than men.

Activated protein $C$ resistance

Functional resistance to the anticoagulant effects of activated protein $\mathrm{C}$ seems to be the most common inherited prothrombotic state. ${ }^{51}$ The genetic basis for this functional abnormality has recently been defined as a point mutation in factor $\mathrm{V}$ at the exact site (Arg 506) where activated protein $\mathrm{C}$ normally cleaves and inactivates the Va procoagulant; this is referred to as the Leiden factor $\mathrm{V}$ mutation. ${ }^{52}$ Some small studies have suggested an association between activated protein $\mathrm{C}$ resistance or the Leiden factor $\mathrm{V}$ mutation and stroke $^{53}$ but larger case-control studies have failed to confirm the association..$^{54-57}$ The situation is complicated by a recent report associating activated protein $\mathrm{C}$ resistance with cerebrovascular disease independent of the factor $\mathrm{V}$ mutation..$^{58}$ In view of the frequency of asymptomatic heterozygotes for the factor $\mathrm{V}$ Leiden mutation in the normal population the optimal treatment of patients with the mutation and stroke is uncertain. However, in young patients with no obvious risk of stroke anticoagulation with warfarin seems a reasonable approach. Paradoxical venous embolism should be sought in view of the strong association with venous thrombosis.
Antithrombin III

Antithrombin III is a plasma glycoprotein synthesised in hepatocytes and endothelial cells, ${ }^{59}$ and encoded for by a gene located on chromosome $1 .{ }^{60}$ It inhibits thrombin and other activated serine proteases including factors IXa, Xa, XIa, XIIa, and calicrin. Congenital antithrombin III deficiency is inherited as an autosomal dominant trait. ${ }^{59}$ The most common defect is mild (heterozygous) antithrombin deficiency which occurs in 1 in 2000 people. In addition, dysfunctional antithrombin molecules with mutations affecting either the serine protease binding site or the heparin binding site have been described. It has been estimated that between 1 in 2000 and 1 in 5000 of the general population have antithrombin III deficiency. ${ }^{61}{ }^{62}$

Antithrombin III deficiency has been associated with a high risk of developing venous thrombosis with as many as $85 \%$ of patients developing thrombosis by the age of $50 .^{63}$ There are case reports linking hereditary antithrombin III deficiency and ischaemic stroke and in some of these stroke occurred in family members, suggesting a causative association. $^{4064-67}$

An acquired antithrombin III state can be caused by severe hepatic failure leading to reduced synthesis of antithrombin III, nephrotic syndrome, oral contraceptive use, heparin therapy, disseminated intravascular coagulation, leukaemia, malnutrition, and diabetes. ${ }^{68}$ Heparin therapy increases antithrombin III activity and rapidly decreases antithrombin III plasma concentrations. The plasma concentrations normalise two to three days after stopping therapy. $^{5}$ Because heparin requires antithrombin to exert its anticoagulant action, treatment of antithrombin III deficiency with heparin alone is inadequate. However, patients with antithrombin III who develop acute thrombosis or embolism can be treated with intravenous heparin initially as there is usually sufficient normal antithrombin to act as a heparin cofactor. However, after this they should be placed on long term warfarin therapy. It is not certain whether lifelong warfarin treatment is required and currently decisions should be made according to the severity of the condition, the family history, and the number of recurrences. ${ }^{44}$ Family studies should be conducted when an antithrombin deficient person is discovered as up to half the members of a kindred may be affected. Asymptomatic subjects with antithrombin III deficiency should receive prophylactic anticoagulation with heparin or antithrombin III concentrate infusions to raise their antithrombin III concentration before medical or surgical procedures which may increase their risk of thrombosis. Chronic oral anticoagulation is not recommended until those at risk have a clinical thrombotic episode..$^{22} \mathrm{~A}$ recent alternative treatment is antithrombin III replacement with antithrombin III concentrates. ${ }^{69}$ 
Fibrinolytic system disorders

CONGENITAL

Plasminogen deficiency

Families have been described with recurrent venous thrombosis and embolism due to defects in fibrinogen or plasminogen, or with decreased synthesis or release of tissue plasminogen activator. There are a few case reports associating low functional levels of plasminogen activity in young people with stroke..$^{70}$

Hereditary dysfibrinogenaemia is characterised by abnormal fibrinogen molecules that are resistant to cleavage by plasmin. This is a rare disorder which has been linked to thrombosis, including strokes. ${ }^{17}$

ACQUIRED

Disseminated intravascular coagulation

Disseminated intravascular coagulation is a rare disease characterised by fibrin thrombi in small vessels and haemorrhagic lesions. It more commonly causes an encephalopathic picture rather than stroke-like episodes although stroke-like episodes may occur. Pathology shows widespread haemorrhagic cerebral infarcts and intracranial haemorrhages. The diagnosis is confirmed by a low platelet count accompanied by low fibrinogen and raised fibrin degradation products.

Lupus anticoagulant/anticardiolipin syndrome The lupus anticoagulant and anticardolipin antibodies are closely related autoantibodies belonging to a group of antibodies which react with proteins associated with phospholipid. Anticardiolipin antibodies seem to be directed against the plasma protein $\beta_{2}$-glycoprotein whereas thrombin is probably the target protein for the lupus anticoagulant. They are most commonly found in patients with systemic lupus erythematosus but may also occur in patients without the disease and are associated with arterial and venous thrombosis. In the absence of systemic lupus erythematosus they may form one part of the antiphospholipid antibody syndrome which can present with recurrent miscarriages, arterial and venous thrombosis in any size vessel, livedo reticularis, cardiac valve vegetations, and thrombocytopenia. ${ }^{72}$ However, anticardolipin antibodies are not specific to the antiphospholipid syndrome and may occur in normal subjects, patients with other autoimmune disorders, malignancy, and HIV infection, and after the use of various drugs including phenytoin, sodium valproate, procainamide, hydrallazine, and quinidine.

Studies have found widely varying frequencies of antiphospholipid antibodies in patients with stroke with a prevalence from 1 to about $50 \% .{ }^{73}{ }^{74}$ A recent study in an unselected stroke population found no evidence to support the hypothesis that anticardolipin antibodies are an independent risk factor for stroke in young people. ${ }^{75}$ There was an increase in IgG titre with age and number of vascular risk factors in patients with stroke, but the authors interpreted this as suggesting that it may be a nonspecific accompaniment of vascular disease. By contrast, a recent study by the Antiphospholi- pid Antibodies and Stroke Study Group found that a single anticardolipin antibody value $\geqslant 10$ GPL units at the time of an initial ischaemic stroke was a significant independent risk factor for stroke but when patients were followed up, anticardolipin antibody positivity did not confer a significantly increased risk for subsequent thrombo-occlusive events or death, including that secondary to stroke. ${ }^{76}$ Therefore the overall contribution of antiphospholipid antibodies to risk of stroke remains uncertain. Such cases are relatively rare and therefore no association may be detected in small studies of unselected stroke patients. The symptoms of cerebral ischaemia may be atypical, sometimes with atypical amaurosis fugax in the absence of carotid artery disease. Nevertheless, in those with persistently high titres of anticardolipin antibody, or a persistently positive lupus anticoagulant and some features of the antiphospholipid syndrome there does seem to be an association between the antiphospholipid antibodies and stroke. In such patients, anticoagulation with an international normalised ratio (INR) $\geqslant 3$ seems to be more effective than low intensity warfarin or aspirin in preventing recurrent thrombosis. ${ }^{78}$ However, in patients with raised anticardolipin antibodies and stroke, in the absence of other features of the antiphospholipid syndrome, the association is more tenuous. In such patients it is sensible to repeat the titre and look for other causes of stroke before treating with anticoagulation.

\section{Pregnancy and the puerperium}

In developed countries stroke complicating pregnancy or the puerperium is rare with a frequency of perhaps only 1 or 2 per 10000 deliveries. ${ }^{79}$ It is more common in India. ${ }^{80} \mathrm{~A}$ proportion of these cases is caused by a prothrombotic state that may result in acute middle cerebral artery or other large cerebral artery occlusion, perhaps due to paradoxical embolism from the pelvic or leg veins, or cerebral venous thrombosis. This most often occurs in the puerperium. ${ }^{81}$

\section{Oral contraceptives}

Studies have shown an increased stroke risk in women taking the oral contraceptive pill. ${ }^{82}{ }^{83}$ Studies assessing the risk of stroke in women on the second and third generation combined oestrogen/progesterone oral contraceptives are only now being published. A recent hospital based case-control study assessed the risk of ischaemic and haemorrhagic stroke in 20-44 year olds in 21 centres around the world. ${ }^{84} 85$ Six hundred and ninety seven cases of cerebral infarction confirmed by CT were compared with 1962 age matched hospital controls and the overall odds of ischaemic stroke were 2.99 (95\% confidence interval (95\% CI) 1.65-5.4) in Europe, and 2.93 (95\% CI 2.15-4.00) in developing countries. Odds ratios were lower in non-smokers, younger women, and those without hypertension. In Europe the odds ratio associated with low dose oral contraceptives was 1.53 (95\% CI $0.71-3.31)$ compared with 5.30 (95\% CI 2.56-11.0) for higher dose oral contraceptives but no such difference was 
found in developing countries. For haemorrhagic stroke 1068 cases and 2910 controls were studied and overall the use of combined oral contraceptives was associated with a slightly increased risk, but only in developing countries (odds ratio 1.76, 95\% CI 1.35-2.30). Current oral contraceptive users and hypertensive women had substantially increased risk. Overall in this study about $13 \%$ of all strokes in women aged 20-44 in Europe are attributed to the use of oral contraceptives and $8 \%$ of strokes in a similar age group in women in developing countries. Significantly increased risks are seen in older women, those who smoke, and those with a history of hypertension. Recently it has been suggested that persons heterozygous for the Leiden factor $\mathrm{V}$ mutation are at increased risk of having ischaemic stroke while on the contraceptive pill.

\section{Paraproteinaemias}

Paraproteinaemias such as Waldenstrom's macroglobulinaemia and multiple myeloma can result in a hyperviscosity syndrome which usually presents with an encephalopathic picture with symptoms such as headache, ataxia, lethargy, poor concentration, visual blurring, and drowsiness and coma. Occasionally focal stroke-like episodes may occur and these may also be secondary to occlusion of vessels with acidophilic material thought to result from the abnormal plasma proteins. ${ }^{23}$

\section{General management considerations}

It is difficult to determine the importance of the various deficiencies of natural anticoagulants in the pathogenesis of stroke in view of the conflicting data that have been published. However, most well controlled studies suggest that their contribution to overall stroke risk is low in the general population of patients with stroke. They are likely to be a more important cause in young patients without other obvious causes for stroke. On current evidence it would seem reasonable to screen for protein $C$, protein $\mathrm{S}$, activated protein $\mathrm{C}$ resistance, and possibly antithrombin III deficiency in such patients aged 55 or under. These tests can be screened for by assays of protein concentrations or functional testing. Interpretation of the results is complicated both by the acute phase changes seen with protein $\mathrm{C}$ and $\mathrm{S}$ and the roughly $5 \%$ prevalence of heterozygotes with the factor $\mathrm{V}$ Leiden mutation in the normal population. These factors have to be carefully considered before embarking on long term anticoagulant treatment in such patients. In general this should only be instituted if there are no other obvious causes for stroke. However, in young patients including children with stroke associated with hereditary deficiencies and a strong family history of stroke in the presence of anticoagulation abnormalities, anticoagulation is usually appropriate. The situation is further complicated by the coexistence of more than one abnormality in some patients which may possibly confer increased stroke risk. ${ }^{69}$
Table 2 Screening for haematological disorders in patients with stroke

\begin{tabular}{ll}
\hline In all cases & Full blood count, erythrocyte \\
& sedimentation rate, plasma viscosity \\
In young stroke & Protein C \\
(age $\leqslant 55)$ & Protein S \\
& Antithrombin III \\
& Lupus anticoagulant \\
& Anticardiolipin antibodies \\
& APC resistance/Leiden factor V mutation \\
& $\star$ Haemoglobin electrophoresis
\end{tabular}

^In subjects of African or Mediterranean origin.

Haematological evaluation in patients with ischaemic stroke

From the above discussion it is clear that haematological causes for stroke are uncommon and that the association between some of these and stroke remains uncertain. All patients with stroke should have a full blood count. A detailed family history should be taken. More detailed haematological assessment should be confined to patients in whom the likelihood of detecting a significant abnormality is greater. This includes younger patients, patients without any other obvious cause for stroke, and those with a strong family history of nonatheromatous stroke. In such patients it is reasonable to screen for protein $\mathrm{C}$, protein $\mathrm{S}$ (and total protein $S$ if abnormal), and antithrombin III deficiencies, activated protein $\mathrm{C}$ resistance, anticardolipin antibodies, and the lupus anticoagulant. If activated protein $\mathrm{C}$ resistance is abnormal factor $\mathrm{V}$ Leiden polymorphism should be determined. When such tests are performed in the acute phase of stroke, particularly in patients with larger strokes, if abnormalities are found the tests should be repeated some weeks later before any long term decisions on management are made. It should be remembered that concurrent anticoagulation therapy (for example, heparin or oral courmarin) will reduce the concentration of the anticoagulant proteins such as protein C and $S$. All young black and eastern Mediterranean people with stroke should have haemoglobin electrophoresis for sickle cell disease. Table 2 summarises this screening proceedure.

\section{Summary}

Haematological disorders account for $0 \%-8 \%$ of ischaemic strokes in different series. These include cellular disorders such as polycythaemia rubra vera, essential thrombocythaemia, sickle cell disease, thrombocytopenia, and other disorders. They also include disorders of coagulation, and recently particular interest has centred on protein $\mathrm{C}$ and $\mathrm{S}$ deficiency and activated protein $\mathrm{C}$ resistance. Antiphospholipid antibodies represent an acquired disorder of coagulation. A prothrombotic state induced by more common factors including the contraceptive pill, pregnancy, and the puerperium, and neoplasia also seems to increase stroke risk. Haematological causes of ischaemic stroke were reviewed in this chapter and a protocol for exclusion of such disorders in patients with ischaemic stroke was discussed.

1 Marcus AJ, Webster BB, Jaffe EA, et al. Synthesis of prostacyclin from platelet derived endoperoxides by culture human endothelial cells. $\mathcal{F}$ Clin Invest 1980;60:979-86. 
2 Radomski MW, Moncada S. Regulation of vascular haemostasis by nitric oxide. Thromb Haeomost 1993;70:3641.

3 Davie EW, Ratnoff OD. Waterfall sequence for intrinsic blood clotting. Science 1964;145:1310-2.

4 MacFarlane RG. An enzyme cascade in the blood clotting mechanism and its function as a biochemical amplifier. Nature 1964;202:498-9.

5 Hart RG, Kanter MC. Haematological disorders and ischaemic stroke: a selective review. Stroke 1990;21:111121.

6 Rosove MH, Hocking WG, Canobbio MM, et al. Cronic hypoxaemia and decompensated erythrocytosis in cyanotic congenital heart disease. Lancet 1986;ii:313-5.

7 Lubarsky Da, Gallagher CJ, Berend JL. Secondary polycythaemia does not increase the risk of perioperative haemorrhagic or thrombotic complications. F Clin Anest 1991;3: 99-103.

8 Preston FE, Martin JF, Stewart RM, et al. Thrombocytosis, circulating platelet aggregates and neurological dysfunction. BMF 1979;ii:1561-3.

9 Jabaily J, Iland HJ, Laszlo J, et al. Neurologic manifestations of essential thrombocythaemia. Ann Intern Med 1983;99: 513-8

10 Schafer AI. Bleeding and thrombosis in the myeloproliferative disorders. Blood 1984;64:1-12.

11 Wood DH. Cerebrovascular complications of sickle cell anaemia. Stroke 1978;9:73-5.

12 Adams RJ, Nichols FT, McVie V, et al. Cerebral infarction in sickle cell anaemia: mechanism based on CT and MRI. Neurology 1988;38:1012-7.

13 Glauser TA, Siegel MJ, DeBaun MR. Accuracy of neurologic examination and history in detecting evidence of MRI-diagnosed cerebral infarctions in children with sickle cell haemoglobinopathy. F Child Neurol 1995;10:88sickle

14 Adams R, Mckie V, Nichols F, et al. The use of transcranial ultrasonography to predict stroke in sickle cell disease. $N$ Engl f Med 1992;326:605-10.

15 Fabian RH, Peters BH. Neurological complications of haemoglobin SC disease. Arch Neurol 1984;41:289-92.

16 Handin RI. Disorders of the platelet and vessel wall. In Issenbacher KJ, Braundwell E, Wilson JD, et al, eds. Harrison's principles of internal medicine. 13th ed. New York: McGraw Hill, 1994:1798-803.

17 Coull BM, Clark WM. Abnormalities of haemostasis in ischaemic stroke. Med Clin 1993;77:77-94.

18 Silverstein A. Thrombotic thrombocytopenic purpure; the initial neurological manifestations. Arch Neurol 1968;18: 358-62.

19 Ridolfi RL, Bell WR. Thrombotic thrombocytopenic purpure; report of 25 cases and review of the literature. purpure; report of 25 cases
Medicine 1981;60:413-28.

20 Kay AC, Solberg LA, Nichols DA, et al. Prognostic significance of computed tomography of the brain in
thrombotic thrombocytopenic purpure. Mayo Clin Proc 1991;66:602-7.

21 Sheth KJH, Swick HM, Haworth N. Neurological involvement in haemolytic-uraemic syndrome. Ann Neurol 1986; 19:90-93.

22 Handin RI. Disorders of coagulation and thrombosis. In Issenbacher KJ, Braundwell E, Wilson JD, et al. Harrison's principles of internal medicine. 13th ed. New York: McGraw Hill, 1994:1804-13.

23 Becker PS, Miller VT. Heparin-induced thrombocytopenia. Stroke 1989;20:1449-59.

24 Massey EW, Riggs JE. Neurologic manifestations of haematologic disease. Neurol Clin 1989;7:549-60.

25 Demirer T, Dail DH, Aboulafia DM. Four varied cases of intravascular lymphomatosis and a literature review. Cancer 1984;76:1738-45.

26 Williams DB, Lyons MK, Takehiko Y, et al. Cerebral angiotrophic large cell lymphoma (neoplastic angioendotheliosis) therapeutic considerations. F Neurol Sci 1991;103:1621 .

27 Glass J. Hochberg FH, Miler DC. Intravascular lymphomatosis. A systemic disease with neurologic manifestatoins. Cancer 1993;71:3156-64.

28 Lennox IM, Zeeh J, Currie $\mathrm{N}$, et al. Malignant angioendotheliosis - an unusual cause of stroke. Scot Med $f$ 1989;34:407-8.

29 Lie JT. Malignant angioendotheliomatosis (intravascular lymphomatosis) clinically simulating primary angiitis of the
central nervous system. Arthritis Rheum 1992:57:831-4.

30 Roux S, Grossin M, De Bandt M, et al. Angiotropic large cell lymphoma with mononeuritis multiplex mimicking 363-6.

31 Tuddenham EGD. Thrombophilia: a new factor emerges from the mists. Lancet 1993;342:1501-2.

32 Miletich J, Sherman L, Broze G. Absence of thrombosis in subjects with heterozygous protein C deficiency. Semin Thromb Hemost 1990;16:166-76.

33 Tait RC, Walker ID, Islam SIAM, et al. Protein C activity in healthy volunteers - influence of age, sex, smoking, and oral contraceptives. Thomb Haemost 1993;70:281-5.

34 Gladson CL, Scharrer I, Hach V, et al. The frequency of type 1 heterozygous protein $S$ and protein $C$ deficiency in 141 unrelated young patients with venous thrombosis. Thromb Haemost 1988;59:18-22.

35 Israels SJ, Seshia SS. Childhood stroke associated with protein C or protein S deficiency. F Pediatr 1987;111:562-4

36 Grewall RP, Goldbert MA. Stroke in protein C deficiency. Am F Med 1990;89:538-9.
37 Kohler J, Kasper J, Witt I, et al. Ischaemic stroke due to protein C deficiency. Stroke 1990;21:1077-80.

38 Camerlingo M, Finazzi G, Caato L, et al. Inherited protein $\mathrm{C}$ deficiency and non-haemorrhagic arterial stroke in young adults. Neurology 1991;41:1371-3.

39 Simioni P, De Rone H, Prandoni P, et al. Ischaemic stroke in young patients with activated protein $\mathrm{C}$ resistance. A report of three cases belonging to three different kindreds. Stroke 1995;26:885-90.

40 Martinez RA, Rangel-Guerra HR, Marfil LJ. Ischaemic stroke due to deficiency of coagulation inhibitors. Report of 10 young adults. Stroke 1993;24:19-25.

41 Van Kuijck MAP, Rotteveel JJ, Van Oostrom CG, et al. Neurological complications in children with protein C deficiency. Neuropaediatrics 1994;25:16-9.

42 D'Angelo A, Landi G, Vigano d'Angelo S, et al. Protein C in acute stroke. Stroke 1988;19:579-83.

43 Kennedy CR, Warner G, Kai M, et al. Protein C deficiency and stroke in early life. Dev Med Child Neurol 1995;37:723-

44 Tatlisumak T, Fisher M. Hematologic disorders associated with ischaemic stroke. F Neurol Sci 1996;140:1-11.

45 Broekmans AW, Van der Linden IK, Jansen Y, et al. Prevalence of protein C (PC) and protein S (PS) deficiency in patients with thrombotic disease. Thromb Res 1986; (suppl VI) 268 .

46 Barinagarrementeria F, Cant A, Cant-Brio C, et al. Prothrombotic states in young people with idiopathic stroke. A prospective study. Stroke 1994;25:287-90.

47 Green D, Otoya J, Oriba H, et al. Protein S deficiency in middle-aged women with stroke. Neurology 1992;42:102933.

48 Sacco RL, Owen J, Mohr JP, et al. Free protein S deficiency: a possible association with cerebrovascular occlusion. Stroke 1989;20:75-80.

49 Davous P, Horelloyu M, Conard J, et al. Cerebral infarction and familial protein S deficiency. Stroke 1990;21:1760-1.

50 Mayer SA, Sacco RL, Hurlet A, et al. Free protein S deficiency in acute ischaemic stroke. Stroke 1993;24:224-7.

51 Svensson PJ, Dahlback B. Resistance to activated protein C as a basis to venous thrombosis. $N$ Engl $f \mathrm{Med}$ 1994;330:517-22.

52 Bertina RM, Koelman BPC, Rosendall FR, et al. Mutation in the blood coagulation factor $\mathrm{V}$ associated with resistance to activated protein C. Nature 1994;369:64-7.

53 Halbmayer WM, Haushofer A, Schon R, et al. The prevalence of poor anticoagulant response to activated protein C (APC resistance) among patients suffering from stroke or venous thrombosis and healthy subjects. Blood Coagul Fibinolysis 1994;5:54-9.

54 Ridker PM, Miletich JP. Mutation in the gene coding for coagulation factor $\mathrm{V}$ and the risk of myocardial infarction, stroke and venous thrombosis in apparently healthy men. $N$ Engl f Med 1995;332:912-7.

55 Catto A, Carter A, Ireland $\mathrm{H}$, et al. Factor V Leiden gene mutation and thrombin generation in relation to the development of acute stroke. Arterioscler Thromb Vasc Biol 1995; 15:783-5

56 Press RD, Liu X-Y, Beamer N, et al. Ischaemic stroke in the elderly. Role of the common factor $\mathrm{V}$ mutation causing resistance to activated protein C. Stroke 1996;27:44-8.

57 Markus HS, Zhang Y, Jeffery S. Screening for the factor-V Arg 506 Gln mutation in patients with TIA and stroke. Cerebrovasc Dis 1996;6:360-2.

58 Van der Bom JG, Bots ML, Havekate F, et al. Reduced response to activated protein $\mathrm{C}$ is associated with increased risk for cerebrovascular disease. Ann Intern Med 1996;125: $265-9$.

59 Lane DA, Caso R. Antithrombin: structure, genomic organisation, function and inherited deficiency. Clin Haematol 1989;2:961-98.

60 Rosenberg RD. Actions and interactions of antithrombin and heparin. N Engl F Med 1975;202:146-51.

61 Bock SC, Harris JF, Balazs I, et al. Assignment of the human antithrombin III structural gene to chromosome Iq23-q25. Cytogenet Cell Genet 1985;39:67-70.

62 Menache D. Replacement therapy in patients with hereditary antithrombin III deficiency. Semin Hematol 1991;28: 31-8.

63 Odegaard OP, Abildgaard U. Antithrombin III: critical review of assay methods. Significance of variations in health and disease. Haemostasis 1978;7:127-34.

64 Vomberg PP, Breederveld C, Fluery P, et al. Cerebral thromboembolism due to antithrombin III deficiency in two children. Neuropaediatrics 1987;18:42-4

65 Simioni P, Zanardi S, Saracino A, et al. Occurrence of arterial thrombosis in a cohort of patients with hereditary deficiency of clotting inhibitors. f Med 1992;23:61-4.

66 Arima T, Motomura M, Nishiura Y, et al. Cerebral infarction in a heterozygous with variant antithrombin III.
Stroke 1992;23:1822-5.

67 Graham JA, Daly HM, Carson PJ. Antithrombin III deficiency and cerebrovascular accidents in young adults. $\mathcal{F}$ Clin Pathol 1992;45:921-2.

68 Hathaway WE. Clinical aspects of antithrombin III deficiency. Semin Haematol 1991;28:19-23.

69 Menache D. Antithrombin III concentrates. Hematol Oncol Clin North Am 1992;6:1115-20.

70 Furlan AJ, Lucas FV, Craciun R, et al. Stroke in a young adult with familial plasminogen disorder. Stroke 1991;22: 1598-602.

71 Nagayama T, Shinohara Y, Nagayama M, et al. Congenitally abnormal plasminogen in juvenile ischaemic cerebrovascular disease. Stroke 1993;24:2104-7. 
72 Hughes GRV. The antiphospholipid syndrome: 10 years on Lancet 1993;342:341-4.

73 Montalban J, Khamashta M, Davalos A, et al. Value of immunologic testing in stroke patients. A prospective multicentre study. Stroke 1994;25:2412-5.

74 Brey RL, Hart RG, Sherman DG, et al. Antiphospholipid antibodies and cerebral ischaemia in young people. Neurology 1990;40:1190-6.

75 Muir KW, Squire IB, Alwan W, et al. Anticardolipin antibodies in an unselected stroke population. Lancet 1994;344:452-6.

76 The Antiphospholipid Antibodies Stroke Study Group (APASS). Anticardolipin antibodies and the risk of recurrent thrombo-occlusive events and death. Neurology 1997;48:91-4.

77 Koller H, Stoll G, Sitzer M, et al. Deficiency of both protein $\mathrm{C}$ and protein $\mathrm{S}$ in a family with ischaemic strokes in young adults. Neurology 1994;44:1238-40.

78 Khamashta MA, Cuadrado MJ, Mujie F, et al. The management of thrombosis in the antiphospholipid-antibody ment of thrombosis in the antiphosph.

79 Grosset DG, Ebrahim S, Bone I, et al. Stroke in pregnancy and the pueperium; what magnitude of risk? F Neurol Neuperas: 129-31.

80 Srinivasan K. Cerebral venous and arterial thrombosis in pregnancy and pueperium; a study of 135 patients. Angiol ogy 1983;35:731-46.
81 Cant C, Barinagarrementeria F. Cerebral venous thrombosis associated with pregnancy and pueperium; review of 67 cases. Stroke 1993;24:1880-4.

82 Royal College of General Practitioners Oral Contraceptive Study. Incidence of arterial disease among oral contraceptive users. Fournal of the Royal College of General Practitioners 1983;33:75-82.

83 Vessey NP, Lawless N, Yeates D. Oral contraceptives and stroke; findings in a large prospective study. $B M \mathcal{F}$ 1984;298:530-1.

84 WHO Collaborative Study of Cardiovascular Disease and Steroid Hormone Contraception. Ischaemic stroke and combined oral contraceptives; results of an international, multi centre, case-controlled study. Lancet 1996;348:498505.

85 WHO Collaborative Study of Cardiovascular Disease and Steroid Hormone Contraception. Haemorrhagic stroke, overall stroke risk and combined oral contraceptives; results of an international, multi centre, case-controlled study. Lancet 1996;348:505-10.

\section{Further reading}

86 Bloom AL, Forbes DC, Thomas DP, et al, eds. Haemostatis and thrombosis. 3rd ed. Edinburgh: Churchill Livingstone, 1994. 